\title{
Definition of a Diagnostic Routine in Individuals with Inconclusive Serology for Chagas Disease
}

\author{
Mariele Cristina Modolo Picka ${ }^{1}$, Domingos Alves Meira ${ }^{1}$, Thaís Batista de Carvalho ${ }^{1}$, \\ Eliana Peresi ${ }^{1}$ and Jussara Marcondes-Machado ${ }^{1}$ \\ ${ }^{1}$ Department of Tropical Diseases and Imaging Diagnosis, Botucatu School of Medicine, UNESP; Botucatu, SP, Brazil
}

\begin{abstract}
Despite the existence of highly sensitive tests, inconclusive serological results are frequent in chronic chagasic infection. This study aimed to define a diagnostic conduct for 30 individuals with inconclusive serology (G3) for chagasic infection assisted at the Outpatient Unit for Infectious and Parasitic Diseases of the Botucatu School of Medicine. Twenty-one individuals with negative serology (G1) and 33 with positive serology (G2) were also studied. Serological methods ELISA, HAI, IFI and immunoblotting TESA-cruzi were used for G1, G2 and G3, and parasitological methods xenodiagnosis, hemoculture and PCR-LIT were used for G2 and G3 individuals. ELISA, HAI and IFI were performed in 5 different blood samples in G2 and G3. TESA-cruzi was carried out only once in G1, G2 and G3 and, since it is the most sensitive, it was utilized as standard. In G3, positivity for ELISA reached $86 \%$ in the fifth blood sample; the ELISA+HAI+IFI combination showed a maximum of $\mathbf{4 4 . 8 \%}$ in the second sample; and TESA-cruzi, $76 \%$ in one single sample. Xenodiagnosis positivity was $9.4 \%$; hemoculture showed $15.2 \%$; and PCRLIT exhibited $22 \%$ positivity in G2. Nevertheless, in G3, positivity percentage was $3.4 \%$ for xenodiagnosis, $6.7 \%$ for PCR-LIT, and no positive result was found for hemoculture. In G3, PCR-LIT resolved one case which was still inconclusive according to serology tests. In order to define inconclusive diagnoses, the results suggest the combined use of ELISA+HAI+IFI in 2 blood samples, decreasing the occurrence of false positive/negative results. If results remain inconclusive, the performance of TESA-cruzi and PCR-LIT, if necessary, is recommended.

Key-Words: Chronic chagasic infection, Trypanosoma cruzi, inconclusive serology, immunoblotting.
\end{abstract}

Trypanosoma cruzi (T. cruzi) affects 5 million people in Brazil [1]. When such agent infects an individual, various immunologic reactions occur in order to eliminate the parasite. Firstly, the cellular immune response attempts to isolate the microorganism, to prevent its dissemination. Simultaneously, humoral response takes place by initially producing IgM class antibodies and IgG antibodies after 2 to 3 weeks. However, due to the inefficiency of such mechanisms, the parasites remain in the organism and trigger an inflammatory response, resulting in tissue damage during the chronic phase of the disease [2].

Although activities for Chagas disease control have been systematized and expanded, the persistence of a large number of chronic patients must be taken into account. In this scenario, laboratory diagnosis, particularly in the indeterminate phase, is of utmost importance, since, once it is confirmed, specific treatment can be commenced [3]. In its chronic form, the infection is not accompanied by signs and symptoms or by alterations in complementary test results. In such phase, laboratory diagnosis is mainly performed by conventional serological tests: ELISA, HAI and IFI [4]. Nevertheless, even with the standardization of tests for such purpose, diagnosis of infection by $T$. cruzi is still complex since inconclusive results are rather frequent.

Received on 13 September 2006; revised 2 March 2007.

Address for correspondence: Dr. Mariele Cristina Modolo Picka. Departamento de Doenças Tropicais e Diagnóstico por Imagem, Universidade Estadual Paulista. Distrito de Rubião Junior s/n. Zip code: 18618-000. Botucatu, SP, Brazil. Phone: 5514 3811-6372. Fax number: 5514 3815-9898 E-mail: mariele@fmb.unesp.br.

Financial support: This paper received financial support from the The State of São Paulo Research Foundation (FAPESP).

The Brazilian Journal of Infectious Diseases 2007;11(2):226-233. (c) 2007 by The Brazilian Journal of Infectious Diseases and Contexto Publishing. All rights reserved.
Pirard et al. [5] recommend the use of 2 serological tests for diagnosing chagasic infection in the selection of blood donors. Similarly, various authors, particularly in Latin America, continue to recommend at least 2 positive serological tests as a criterion for defining chronic chagasic infection [6-8]. The results obtained from conventional tests may be positive, negative or inconclusive, and Umezawa et al. [9] report that a diagnosis is regarded as inconclusive when only 1 of 3 serological tests used is positive, or when they do not express the positive or negative standards of the methods.

Laboratory diagnosis can also be achieved by parasitological methods, such as xenodiagnosis and hemoculture. These methods allow the multiplication of existing parasites in the blood samples; however, they exhibit low sensitivity due to the low parasitemia found in individuals with the chronic form of the disease [3,10]. Recent molecular assays, such as PCR, have been proposed as a good alternative for $T$. cruzi detection [11,12]. One of the most studied structures has been the kinetoplast, which represents a DNA-rich region (kNDA) and is present in all flagellates belonging to the order Kinetoplastida, including T. cruzi $[13,14]$. Although much better than the parasitological tests, this method is also limited for individuals with very low or intermittent parasitemia [15].

Another technique that has been presently studied for diagnosis of chronic-phase chagasic infection, particularly in cases of doubtful serology, is immunoblotting, a bidimensional type of electrophoresis with transference in nitrocellulose membranes which shows the existence of antibodies in patient sera [3]. Extracts of trypomastigote forms of $T$. cruzi are used in these reactions. The semi-purified antigen, denominated TESA (trypomastigote excreted-secreted antigen), has been used by various authors [16-18]. An immunoenzymatic test denominated TESA-blot evaluated 111 samples from nonchagasic patients, including cases of leishmaniasis and other 
pathologies as well as 401 samples from chagasic patients in the acute chronic phases and with congenital transmission, showing $100 \%$ specificity in both groups [19].

This study aimed to define a standard diagnostic conduct using immunologic and parasitological methods for individuals with inconclusive serological tests for chagasic infection and assisted at the General Outpatient Unit for Infectious and Parasitic Diseases of the Botucatu School of Medicine - Unesp.

\section{Materials and Methods}

Area Studied

Eighty-four individuals from the region of Botucatu in the mid-western region of São Paulo state and an old area of Chagas disease transmission were studied.

\section{Population Studied}

\section{Group 1}

Twenty-one male and female blood donors at the hemocenter of the Botucatu School of Medicine (Unesp), who were older than 18 years and with negative serological results for chagasic infection in ELISA and HAI tests performed on one blood sample, comprising the negative control group. None of them informed epidemiological antecedents for chagasic infection.

\section{Group 2}

Thirty-three male and female patients, older than 18 years and with positive result in at least 2 of the serological tests performed, ELISA, HAI and IFI, in the first blood sample collected, comprising the positive control group. All of them reported epidemiological antecedents for chagasic infection (rural zone, housing conditions and vector knowledge).

\section{Group 3}

Thirty male and female individuals, older than 18 years and with positive result in only 1 of the 3 serological tests performed, ELISA, HAI and IFI, or whose results did not express the positive or negative standards of such methods in the first blood sample collected, comprising the inconclusive group. These individuals reported favorable epidemiological antecedents to chagasic infection.

The individuals in G2 and G3 were regularly assisted at the General Outpatient Unit for Infectious and Parasitic Diseases of the Botucatu School of Medicine (Unesp).

\section{Conventional Serological Tests}

Conventional serological tests, ELISA, HAI and IFI, were performed with up to 5 repetitions on different blood samples in G2 and G3 and only once in G1. Blood collections for G2 and G3 were made in 3 different moments of the individuals outpatient care. The regular commercial kits routinely used at the University Hospital of the Botucatu School of Medicine, Hemobio Chagas (Embrabio), Imuno-HAI Chagas (Wama) and Fluocon IgG/IgM (Wama) were utilized according to the manufacturers’ instructions.
Immunoblotting

TESA-cruzi kit bioMériex Brasil AS, which is still not commercially available, was used. TESA-cruzi immunoblotting was performed only once in G1, G2 and G3. Nitrocellulose strips were placed in bands with $1 \mathrm{~mL}$ of sample diluent (milk protein in a buffer - $10 \mathrm{mM}$ TRIS, pH 7.4, 154 mM sodium chloride and $0.1 \%$ L5 Bronidox) and agitated for 1 minute until the strips became moist. Ten $\mu \mathrm{L}$ of the serum samples of each individual were added to each band. The strips were agitated for 2 hours, and the content of each band was later aspirated. One mL of the washing buffer (10 mM TRIS, pH 7.4 and 154 $\mathrm{mM}$ sodium chloride) was added, and agitation was maintained for 5 minutes. The content was aspirated, and the previous step was repeated 4 times. Later, $1 \mathrm{~mL}$ of the human peroxidasestained anti-IgG conjugate was added (human-peroxidase antiIgG in 10 mM TRIS buffer, pH 7.3, 0.2\% phenol and 0.0001\% sodium mercurothiolate) to each band, and agitation was maintained for 1 hour. The content was aspirated, and the band was washed as previously described. One $\mathrm{mL}$ of chromogen solution (3.36 mM of 4-chloronaphtol in alcoholic solution) was added to each band in 4-chloronaphtol diluent (1:5) (Tris-mM buffer, $\mathrm{pH} 7.4,154 \mathrm{mM}$ sodium chloride, 0.03\% hydrogen peroxide and $0.1 \%$ L5 Bronidox). Agitation was carried out for 10 minutes, and the band content was aspirated. In order to interrupt color development, the bands were washed twice with distilled water. The strips were transferred to filter paper and allowed to dry naturally. The presence of bands in the 120 -to-200 $\mathrm{kDa}$ molecular mass region on the strips indicated a positive result and the absence of such bands showed a negative result. For very low or doubtful reactions, the result was regarded as inconclusive.

\section{Artificial Xenodiagnosis}

This method was utilized only once in G2 and G3 individuals. Forty first-stage non-infected Dipetalogaster maximus nymphs from the Tropical Diseases Research Laboratory of the Botucatu School of Medicine - Unesp were used for each individual. The nymphs were fed through the membrane of a non-lubricated condom containing $9 \mathrm{~mL}$ of blood with sodium citrate from each individual, at room temperature for 40 minutes. Thirty days after repast, feces obtained by abdominal compression or the triturate of the digestive tube of each nymph were examined between the slide and cover slip on light microscope (400 to 1000 magnification). Moving flagellated forms of T. cruzi were visualized in positive tests.

\section{Hemoculture in LIT Medium}

This method was performed only once in G2 and G3 individuals. Liver-infusion tryptose (LIT) was used as the culture medium for T. cruzi cultivation. For sample cultivation, $10 \mathrm{~mL}$ of blood from each individual added with coagulant were distributed in 3 tubes containing $5 \mathrm{~mL}$ of LIT medium each. The tubes were maintained at $28-30^{\circ} \mathrm{C}$ and homogenized every 2 days. After the first 15 days and then fortnightly, 
following such initial period and up to a maximum of 180 days, $5 \mu \mathrm{L}$ of the culture medium were placed between the slide and the cover slip for reading on a light microscope (400 to 1,000 magnification). Flagellated forms of $T$. cruzi were visualized in positive tests.

\section{PCR-LIT}

After 180 days of cultivation, the hemocultures in LIT medium were washed in PBS ( $\mathrm{pH} 7.2$ ) twice or 3 times, and the sediment was stored at $-80^{\circ} \mathrm{C}$ until use. DNA extraction from these samples was performed by using the $\mathrm{GFX}^{\mathrm{TM}}$ Genomic Blood DNA Purification kit (Amersham Biosciences). Primers S35(5`-AAATAATGTACGGGGGAGATGCATGA-3`) and S36 (5‘-GGGTTCGATTGGGGTTGGTGT-3`) were used for PCR performance as described by Sturn et al. [13], who amplified the fragment of 330 pairs of bases containing the DNA minicircle regions of the parasite's kinetoplast. Thermocycler amplification conditions were: 1 cycle at $96^{\circ} \mathrm{C}$ for 2 minutes; 3 cycles for 1 minute each at $94^{\circ} \mathrm{C}, 60^{\circ} \mathrm{C}$ and $72^{\circ} \mathrm{C}$, respectively; 1 cycle at $72^{\circ} \mathrm{C}$ for 10 minutes. Eight- $\mu \mathrm{L}$ samples of $100 \mathrm{bp}$ DNA Ladder were used as molecular weight markers. Products amplified from the T. cruzi " $y$ ” strain maintained by the Tropical Diseases Research Laboratory of the Botucatu School of Medicine - Unesp were used as positive control.

\section{Statistical Analysis}

The difference in positivity between the laboratory methods combined 2 to 2 was calculated by $\chi^{2}$ and p using the McNemar method or by direct p calculation through binomial distribution when necessary. The results of serological methods (ELISA, HAI and IFI) and those of their combination were compared with the results provided by immunoblotting by $\chi^{2}$ and $p$ using the Stwart-Maxwell method for 2 paired samples and the trichotomic event. The number of recommended repetitions for each one of the ELISA, HAI and IFI tests in individuals showing inconclusive results for such tests was verified by the proportion of agreement of each test with immunoblotting. Graphic procedure was used to evaluate the point from which there was no increase in the positivity proportion of serological tests as well as to evaluate the proportion of agreement of each conventional serological test with TESA-cruzi.

\section{Results}

Taquarituba, SP, was the municipality which showed the highest concentration of G2 (21.2\%) and G3 (30.0\%) individuals (Figure 1). Twenty (66.6\%) out of $30 \mathrm{G} 2$ and 22 (73\%) out of 30 G3 individuals were males. Also, no difference was found in the mean age for males and females (51 years old) in these 2 groups.

The results of each serological test used in 5 different blood samples, showed the best results for ELISA with 100\% positivity in the $1^{\text {st }}, 2^{\text {nd }}, 3^{\text {rd }}$ and $5^{\text {th }}$ samples of G2. HAI, with positivity between $96.9 \%$ (the $1^{\text {st }}$ and $4^{\text {th }}$ samples) and $90.9 \%$ ( $3^{\text {rd }}$ sample), displayed an intermediate behavior. Despite showing $100 \%$ positivity in the $1^{\text {st }}$ and $5^{\text {th }}$ samples, IFI results oscillated between values lower than $90 \%$ in the other samples and presented the worst results. When ELISA and HAI results were analyzed together in each one of the 5 samples from G2 patients, positivity varied from $96.9 \%$ ( $1^{\text {st }}$ sample) to $90.9 \%$ ( $3^{\text {rd }}$ sample). The analysis of ELISA, HAI and IFI results altogether showed $100.0 \%$ positivity in the $1^{\text {st }}$ and $5^{\text {th }}$ samples, varying from $93.9 \%$ to $96.9 \%$ in the others (Figure 2).

In G3, ELISA was also the most effective method; however, positivity was, at the most, $86.6 \%$ and only in the $5^{\text {th }}$ blood sample analyzed. HAI showed much lower positivity, $41.3 \%$ in the $2^{\text {nd }}$ sample, and IFI exhibited the lowest percentages of positive results among the conventional tests used, with $12.5 \%$ in the $3^{\text {rd }}$ sample as the best result. Positivity of ELISA and HAI tests, analyzed together, oscillated between $17.0 \%$ and $38.0 \%$ in the 5 blood samples. When the 3 serological tests were conjointly analyzed, the results were inconclusive in the first sample: either only one was positive or the values obtained did not express the positive or negative standards of each of the methods. In the second sample, $44.8 \%$ positivity was obtained with this set while only $36.6 \%$ was found in the fifth sample (Figure 3).

The comparison of results from the ELISA test with those of TESA-cruzi when both were performed in one single sample showed that, although TESA-cruzi (22/29) numerically presented greater positivity than ELISA (19/29), such difference was not significant, indicating a positive agreement between the methods ( $p>0.10)$ in G3 individuals. This was not observed when comparing TESA-cruzi with HAI and IFI. TESA-cruzi showed a positive result in 22 and HAI in 3 of the 29 G3 individuals undergoing both methods, thus showing that there was no positive agreement $(\mathrm{p}<0.001)$ between them. The same was observed for IFI, which was positive in 2, and TESA-cruzi which was also positive in 12 of the 17 G3 individuals undergoing both methods.

The TESA-cruzi results were also compared with those of ELISA, HAI and IFI tests when conjointly analyzed in the first blood sample from G1, G2 and G3. In such comparison, agreement was found between G1 and G2. Nevertheless, in G3, TESA-cruzi proved to be better $(\mathrm{p}<0.001)$ than the other conjointly evaluated methods in order to express positivity (Table 1). Figure 3 shows the TESA-cruzi results in G1 and G2 individuals.

Parasitological tests used in G2 and G3 showed poor positivity. Hemocultures showed $15.2 \%$ positivity (5/33) in G2, with no positive results in G3; artificial xenodiagnosis was positive in $9.4 \%$ (3/32) of G2 individuals and in 3.4\% (1/29) of those in G3; PCR-LIT positivity was $24.1 \%$ (7/32) in G2 and $6.7 \%(2 / 30)$ in $\mathrm{G} 3$. In general, there was no equivalence of parasitological methods within the same group: the 5 positive results in G2 by hemoculture did not correspond to the 3 positive results seen in xenodiagnosis. But in PCR-LIT, 2 of the 7 positive G2 individuals were positive by hemoculture.

The comparison of parasitological methods with TESAcruzi in G1 and G2 showed a better performance by 
Table 1. Comparison between ELISA + HAI + IFI and TESA-cruzi positivity in individuals with positive (G2), negative (G1) and inconclusive (G3) serology for chagasic infection

\begin{tabular}{|c|c|c|c|c|}
\hline ELISA+HAI+IFI positivity/TESA-cruzi & $\begin{array}{c}\text { G2 } \\
\text { N (\%) }\end{array}$ & $\begin{array}{c}\text { G1 } \\
\text { N (\%) }\end{array}$ & $\begin{array}{c}\text { G3 } \\
\text { N (\%) }\end{array}$ & $\begin{array}{c}\text { Total } \\
\text { N (\%) }\end{array}$ \\
\hline Positive & 33 (39.30) & $0(0.00)$ & $23(27.40)$ & 56 (66.60) \\
\hline Negative & $0(0.00)$ & $21(25.00)$ & $04(4.80)$ & $25(29.80)$ \\
\hline Inconclusive & $0(0.00)$ & $0(0.00)$ & $03(3.60)$ & $03(3.60)$ \\
\hline Agreement & $\begin{array}{l}\text { Positivity } \\
\text { proportion }\end{array}$ & $\begin{array}{c}\text { Calculated } \\
\text { statistic }\end{array}$ & Significance & Comment \\
\hline TESA-cruzi & $\begin{array}{l}56 / 84(0.6667) \\
33 / 84(03939)\end{array}$ & $\chi^{2}=27.00$ & $\mathrm{p}<0.001$ & Tc $>$ ELISA \\
\hline
\end{tabular}

Table 2. Comparison between TESA-cruzi and artificial xenodiagnosis, hemoculture in LIT medium and PCR-LIT tests in individuals with positive (G2) and inconclusive (G3) serology for chagasic infection

\begin{tabular}{cccc}
\hline $\begin{array}{c}\text { Positivity/ } \\
\text { Group }\end{array}$ & $\begin{array}{c}\text { Hemoculture/ Xenodiagnosis/ } \\
\text { Tc }\end{array}$ & $\begin{array}{c}\text { PCR-LIT/ } \\
\text { Tc }\end{array}$ \\
\hline G2 & $5 / 33$ & $3 / 32$ & $7 / 32$ \\
G3 & $0 / 23$ & $1 / 22$ & $2 * / 23$ \\
\hline
\end{tabular}

$\mathrm{p}<0.001$. Comment: agreement between Tc and hemo, xeno and PCR-LIT was not observed for chagasic infection in the positive (G2) or inconclusive (G3) groups. *One of the individuals presenting positive PCR-LIT showed negative xenodiagnosis and hemoculture and inconclusive ELISA + HAI + IFI and TESA-cruzi. immunoblotting $(\mathrm{p}<0.001)$. Only 1 of the $3 \mathrm{G} 3$ individuals, who remained inconclusive according to TESA-cruzi, showed a positive parasitological method by PCR-LIT (Table 2). The PCR-LIT results of G2 individuals are shown in Figure 5.

\section{Discussion}

The need to clarify the real condition of individuals with inconclusive serology for chagasic infection in this study becomes evident from the information concerning the places of origin of the individuals under study, once it was observed that not only were most of the chagasic individuals (G2) originally from Taquarituba, but so were those with inconclusive serology (G3). This municipality from the mid-

Figure 1. Characterization of individuals with positive (G2) and inconclusive (G3) serology for chagasic infection, according to municipality of origin in São Paulo state.

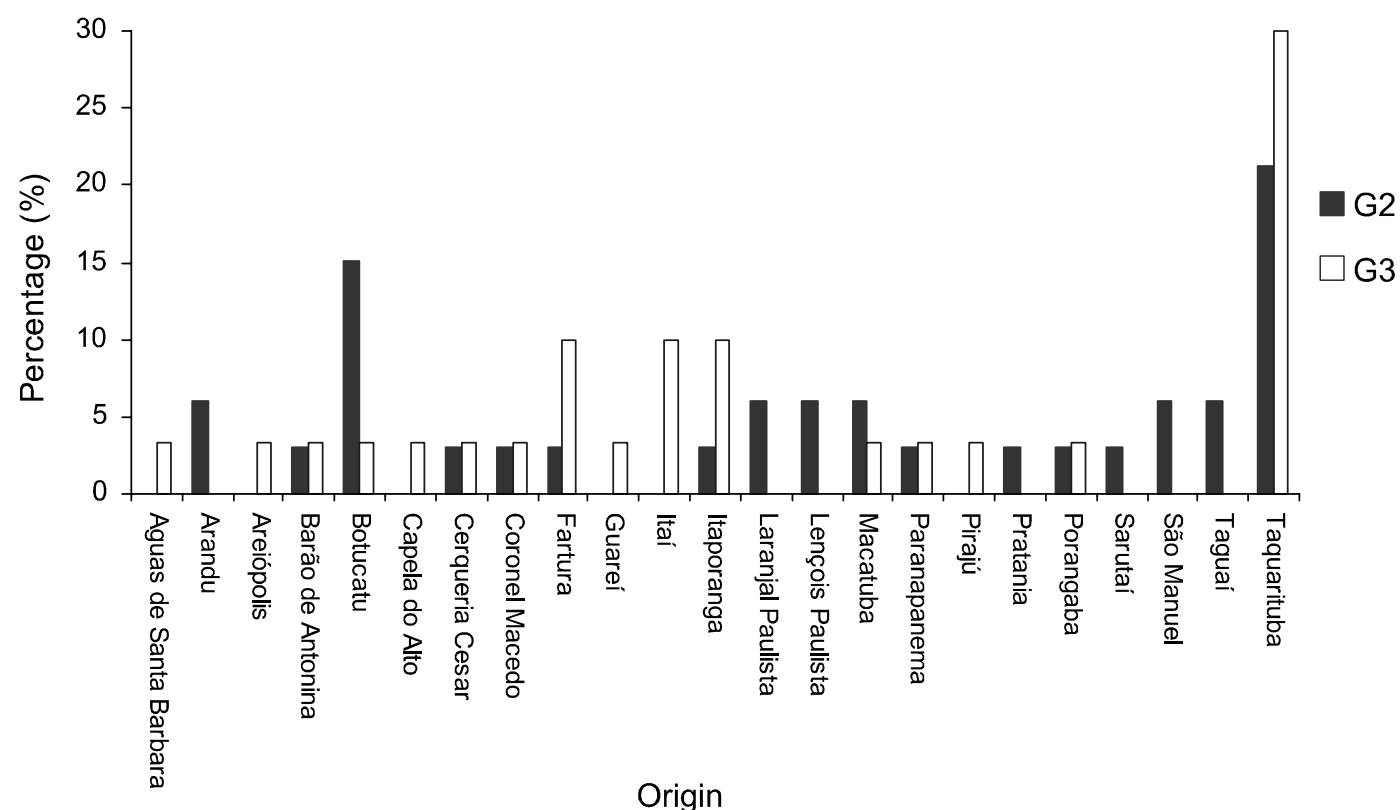


Figure 2. Results of isolated and combined ELISA, HAI and IFI tests in 5 different blood samples from patients in the positive group (G2).

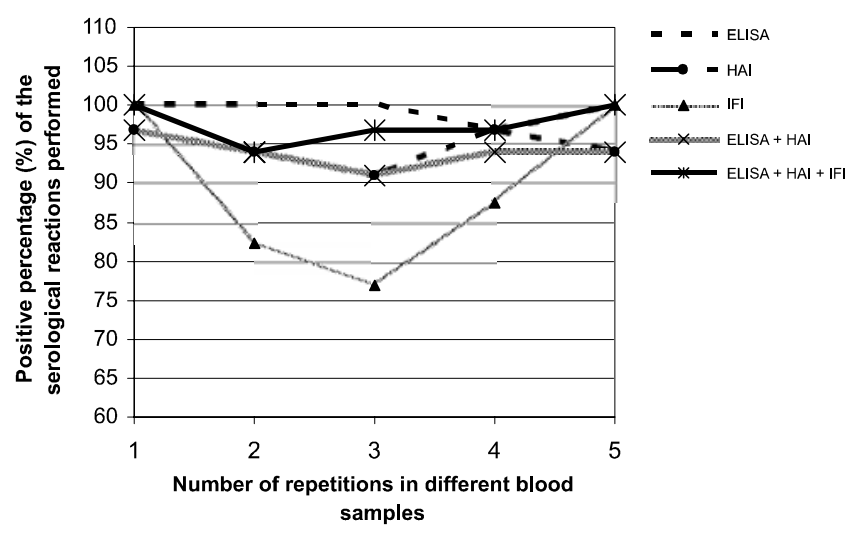

Figure 4. Electrophoresis in agarose gel of the products from 330pb of T. cruzi kDNA-PCR amplified with S35 and S36 primers and stained with ethidium bromide. $\mathrm{P}=$ standard molecular weight; 1 - 12=samples of hemoculture material in LIT medium from individuals with positive serology for chagasic infection (G2); PC=positive control, hemoculture material in LIT medium from Balb/C mice infected with the $T$. cruzi "y" strain.

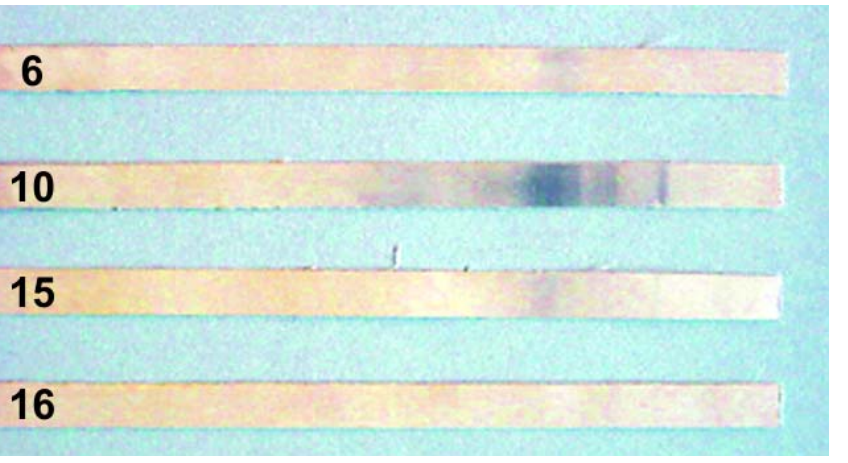

western region of São Paulo state was already reported as an important disseminator of the parasitosis in 1952, a decade when a large part of the sample in this study was probably infected [20]. Data from a sero-epidemiological enquiry conducted at that time showed that $66.7 \%$ of the individuals dwelling in houses with triatomines presented positive serology for chagasic infection, representing the highest percentage recorded in the state [20]. In 1974, even after years following the adoption of measures to eradicate the vector, triatomine domiciliation still persisted in Taquarituba, and $6.6 \%$ of the specimens then captured were contaminated by T. cruzi [21].

The high concentration of males in this sample is explained by the fact that positive and inconclusive individuals were found as such during blood donation screening. This is
Figure 3. Results of isolated and combined ELISA, HAI and IFI tests in 5 different blood samples from patients in the inconclusive group (G3).

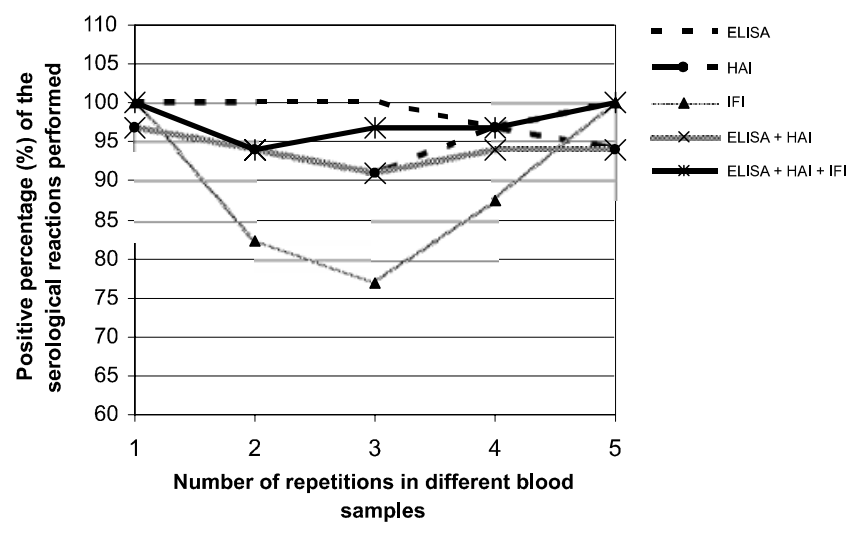

Figure 5. TESA-cruzi. 6,10,15: nitrocellulose membranes of individuals in the positive group indicating bands in the 120to-200-kDa molecular weight region. 16: nitrocellulose membrane of an individual in the negative group: absence of bands.

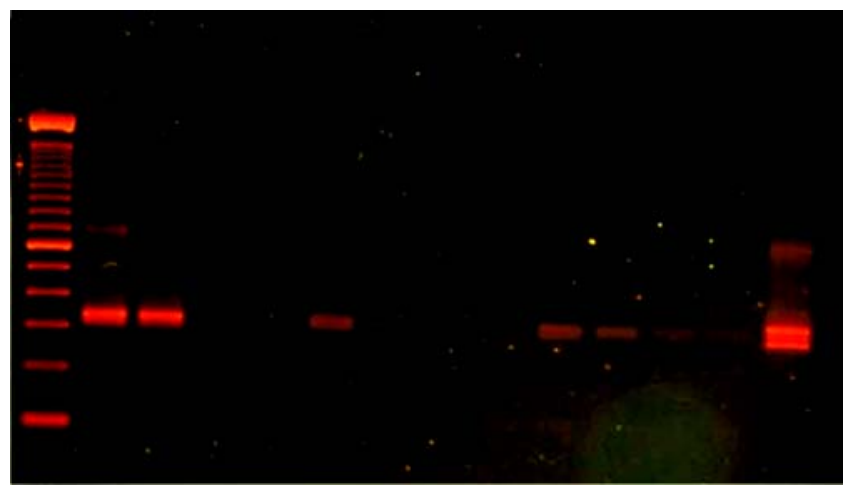

also observed in other Brazilian and South American studies with samples portraying similar characteristics $[5,18]$. In Brazil, studies show that $62 \%$ to $97 \%$ of donors are males [22-28]. Also, the mean age of G2 and G3 individuals was similar to that of blood donation candidates found to be serologically positive for chagasic infection [29]. Studies on individuals already manifesting signs and symptoms of the disease, which did not occur in this investigation, show a higher age mean [30].

The ELISA method was distinguished among the serological methods used in the diagnostic routine of chagasic infection. Because it presents high sensitivity and specificity, it is also indicated as the only serological method for seroepidemiological enquiries that can determine the prevalence 
of the infection [5,31-33]. However, in clinical settings, the result of only 1 serological test is insufficient to diagnose the condition of the chronic T. cruzi carrier [5-8]. HAI shows great sensitivity variations with better specificity [5,33-35]. In this study, that method exhibited low sensitivity, particularly for the inconclusive group (G3). Nevertheless, due to its good specificity, HAI can be used with other serological tests for diagnosing chagasic infection. Gadelha et al. [36] compared the ELISA and HAI methods in a group of individuals from an endemic region who were suspected to carry the disease and showed $92 \%$ positivity for ELISA, without any inconclusive results. HAI, on the other hand, presented a positive result in $59 \%$ of the samples and an inconclusive one in $33 \%$. Nevertheless, the conjoint analysis of the 2 methods showed $52.6 \%$ positivity and $45.5 \%$ inconclusive results [36]. Therefore, when the diagnosis is based on 2 serological methods, inconclusive results tend to increase, but such practice presents false positives and cross reactions [37,38]. When isolatedly used in this study, IFI, a method with very variable good sensitivity and specificity, showed the lowest positivity percentages in G2 and particularly in G3 $[5,31,33,34,35]$. However, its use, conjointly with ELISA and HAI, increases the occurrence of positive results when the methods are together analyzed. The use of 3 serological methods, although not solving all inconclusive cases, is recommended in the lack of a definitive test, since it allows for greater safety in the final diagnosis of chagasic infection.

The disagreement observed in the results of conventional serological tests responsible for inconclusive diagnoses may be related to the parasite capacity of evading the host defense mechanisms. When $T$. cruzi infects men, the production of IgM antibodies is induced; such antibodies then bind to the parasite surface, thus interfering with the binding of IgG inhibition antibodies and consequently preventing $T$. cruzi elimination $[39,40]$. Another strategy used by $T$. cruzi is antigen variation in face of an immune response aiming at host protection. Such modifications are also related to morphological variations in the parasite biological cycle, which involves various antigens in their different phases [41]. Additionally, the T. cruzi's genome is highly complex and repetitive, which facilitates genetic recombination and enhancement of devices that allow the parasite to escape the attacks from the host immune system [42]. At the same time, T.cruzi produces plenty of surface protein variants that enable parasite to avoid antibodies [41]. These are mechanisms that can alter the recognition of such proteins by antibodies, leading to variations in the responses to serological tests of the same individual at different moments. Genetic diversity of T. cruzi lineages infecting different individuals may be responsible for the differences in the titles of antibodies found as well as for clinical manifestations in the chronic phase of Chagas disease [41,43,44].

In face of the need for good-sensitivity serological tests which are capable of solving the problem of inconclusive results, various authors have developed the immunoblotting technique using different $T$. cruzi antigens. Matsumoto et al. [17], for instance, applied such test in individuals from an endemic region. Results were found to be negative among the blood donors; however, $82.2 \%$ of those with positive ELISA and IFI showed themselves reagents to immunoblotting. In the same study on individuals with active visceral leishmaniasis and cross reaction with chagasic infection, 20\% positivity was found by ELISA and IFI. Umezawa et al. [45] detected specific antibodies in 100\% of acute and chronic chagasic patients with positive ELISA and IFI from endemic and non endemic areas. Those authors also studied blood donors from an endemic area, individuals with mucocutaneous and visceral leishmaniasis from non endemic areas, patients infected by $T$. rangeli or with other pathologies, whether infectious or not, and all of them presented negative results for immunoblotting. When applying the test that they developed in blood donation candidates with inconclusive serology, Silveira-Lacerda et al. [18] found only $2.87 \%$ positivity.

By using the same immunoblotting utilized in this study, namely TESA-cruzi, Amato Neto et al. [16] found agreeing results with those obtained by conjointly analyzed ELISA, HAI and IFI in the case of negative and positive individuals for chagasic infection as occurred with G1 and G2. However, the $20 \%$ positivity found by the authors for inconclusive patients when using TESA-cruzi differed from that of G3 individuals, which was $76.6 \%$ (23/30). Amato et al. [16] also found $6.6 \%$ positivity in the TESA-cruzi test of patients with visceral leishmaniasis. The application of DiaMed-IT LEISH (IVD), a method which detects anti-leishmania antibodies, in G3 individuals, showed no positivity.

Regarding the parasitological methods, the results obtained in this study confirmed the mild parasitemia in individuals in the chronic phase of chagasic infection. Although hemoculture always indicates the low sensitivity of such methods, a great deal of disagreement is found in its results when different studies are analyzed, which may be related to the nature of the culture medium, the technique employed, the volume of blood used or the number of test repetitions in each patient [46-49]. Concerning xenodiagnosis, the experiences of different authors also disagree, and that may be related to the different vector species used, the method of nymphs visualization and the amount of blood utilized [7,50].

PCR also shows limited sensitivity in individuals with very low or intermittent parasitemia. By using PCR to assess satellite DNA from T. Cruzi nuclei in an experimental model, Dias et al. [51] observed that, in spite of positive results in mice organs and tissues, results were negative when total blood was used. Similarly, no positive results were found for PCR assessment of the blood in G2 and G3 individuals. In a study conducted by our group on dogs belonging to T. cruziinfected individuals, Lucheis et al. [52] found 50\% positive PCR in hemoculture material in LIT medium. In general, PCRLIT was the parasitological method that presented the 
greatest positivity among G2 and G3 individuals. Additionally, it resolved 1 of the 3 G3 cases which remained inconclusive by the serological methods used, including TESA-cruzi.

In the final analysis of the findings in this study, TESAcruzi was distinguished as the test showing the best possibility to resolve the inconclusive serology for chagasic infection. If it is not available, 2 repetitions of the ELISA, HAI and IFI combination should be performed in different blood samples. In this study, PCR-LIT was the parasitological method that resolved 1 of the 3 cases left inconclusive by the serological methods used.

\section{Acknowledgement}

The authors are indebted to Cristina Mary Orikaza and Carlos Roberto Gonçalves Lima from the Tropical Diseases Research Laboratory of the Botucatu School of Medicine Unesp.

\section{References}

1. World Health Organization. Chagas disease, Brazil: interruption of transmission. Weekly Epidemiological Record 2000;75:1536.

2. Tarleton R.L.Parasite persistence in the aectiology of Chagas disease. Int J Parasitol 2001;31:550-4.

3. Ferreira M.S., Lopes E.R., Chapadeiro E., et al. Doença de Chagas. In: Veronesi R, Focaccia R. Tratado de infectologia. São Paulo: Atheneu; 1997.

4. Luquetti J.A., Rassi A. Diagnóstico laboratorial da infecção pelo Trypanosoma cruzi. In: Brener Z., Andrade Z.A., Barral-Neto M., editores. Trypanosoma cruzi e doença de Chagas. 2a ed. Rio de Janeiro: Guanabara Koogan: 2000.

5. Pirard M., Lihoshi N., Boelaert M., et al. The validity of serologic tests for Trypanosoma cruzi and the effectiveness of transfusional screening strategies in a hyperendemic region. Transfusion 2005;45:554-61.

6. Streiger M.L., del Barco M.L., Fabbro D.L., et al. Longitudinal study and specific chemotherapy in children with chronic chagas disease, residing in a low endemicity area of Argentina. Rev Soc Bras Med Trop 2004;37:365-75.

7. Pompilio M.A., Dorval M.E., Cunha R.V., et al. Epidemiological, clinical and parasitological aspects of Chagas' disease in Mato Grosso do Sul State. Rev Soc Bras Med Trop 2005;38:473-8.

8. Maldonado C., Albano S., Vettorazzi L., et al. Using Polymerase Chain Reaction in early diagnosis of re-activated Trypanosoma cruzi infection after heart transplantation. J Heart Lung Transplant 2004;23:1345-8.

9. Umezawa E.S., Bastos S.F., Coura J.R., et al. An improved serodiagnostic test for Chagas' disease employing a mixture of Trypanosoma cruzi recombinant antigens. Transfusion 2003;43:91-7.

10. Gomes YM. PCR and sero-diagnosis of Chagas'disease: biotechnological advances. Appl Biochem Biotechnol. 1997;66:107-19

11. Britto C., Cardoso M.A., Vanni C.M.M., et al. Polymerase chain reaction detection of Trypanosoma cruzi in human blood samples as a tool for diagnosis and treatment evaluation.. Parasitology 1995;110:241-7.

12. Junqueira A.C.V., Chiari E., Wincker P. Comparison of the polymerase chain reaction with two classical parasitological methods for the diagnosis of Chagas disease in an endemic region of north-eastern Brazil. Trans R Soc Trop Med Hyg. 1996;90:129-32.
13. Sturm N.R., Degrave W., Morel C., Simpson L. Sensitive detection and schizodeme classification of Trypanosoma cruzi cells by amplification of kinetoplast minicircle DNA sequences: use in diagnosis of Chagas' disease. Mol Biochem Parasitol 1989;33:205-14.

14. Avila H.A., Sigman D.S., Cohen L.M., et al. Polymerase chain reaction amplification of Trypanosoma cruzi kinetoplast minicircle DNA isolated from whole blood lysates: diagnosis of Chagas'disease. Mol Biochem Parasitol 1991;48:211-22.

15. Gomes M.L. Trypanosoma cruzi: use of an optimized PCR method in chronic chagas disease diagnosis, and molecular characterization of strains isolated from chronic chagasic individuals living in northwest Paraná, Brazil. Revista da Sociedade Brasileira de Medicina Tropical 1998;31:327-8.

16. Amato Neto V., De Marchi C.R., Ferreira C.S., Ferreira A.W. Observations on the use of TESA blot for the serological diagnosis of Chagas' disease. Rev Soc Bras Med Trop 2005;38:534-5.

17. Matsumoto T.K., Cotrim P.C., da Silveira J.F., et al. Trypanosoma cruzi: isolation of an immunodominant peptide of TESA (trypomastigote excreted-secreted antigens) by gene cloning. Diagn Microbiol Infect Dis 2002;42:187-92.

18. Silveira-Lacerda E.P., Silva A.G., Junior S.F., et al. Chagas ' disease: application of TESA-blot in inconclusive sera from a Brazilian blood bank. Vox Sang 2004;87:204-7.

19. Umezawa E.S., Silveira J.F. Serological diagnosis of Chagas disease with purified and defined Trypanosoma cruzi antigens. Mem Inst Oswaldo Cruz 1999;94:285-8.

20. Unti O., Silva T.L. da. Levantamento da moléstia de Chagas no estado de São Paulo pela reação sorológica. Arquivos de Higiene e Saúde Pública 1952:17:123-32.

21. Mello C da Silva A., Rocha e Silva E.O., et.al. Estudo epidemiológico relativo à infecção chagásica no município de Taquarituba, SP, realizado no período de 1974 a 1976 . In: Resumos do $19^{\circ}$. Congresso Brasileiro de Higiene. São Paulo, 1977.

22. Soares B.C., Proietti A.B., Proietti F.A. HTLV-I/II and blood donor: determinants associated with seropositivity in a low risk population. Rev Saúde Pública 2003;37:470-6.

23. Paltanin L.F., Reiche E.M.V. Seroprevalence of anti hepatitis C virus of antibodies among blood donors, Brazil. Revista de Saúde Pública. 2002;36:393-9.

24. Valente V.B., Covas D.T., Passos A.D.C. Hepatitis B and C serologic markers in blood donors of the Ribeirão Preto Blood Center. Rev Soc Bras Med Trop 2005;38;488-92.

25. Ishak R, Ishak MOG, Azevedo VN, et al. Detection of HTLV-IIa in blood donors in an urban area of the Amazon Region of Brazil (Belém, PA). Revista da Sociedade Brasileira de Medicina Tropical 1998;31:139-97.

26. Prudêncio B.C.A.B., Covas D.T., Bonini-Domingos C.R. Comparação de metodologia utilizada para a deteç̧ão de Hemoglobina S (Hb S) em doadores de sangue. Revista Brasileira de Hematologia e Hemoterapia 2000;22:99-109.

27. Borges VL, Martinez EZ, Bendini MH, Costa MAGF, Ferreira SCL. Reliability of a blood donor satisfaction questionnaire. Revista Brasileira de Epidemiologia 2005;8:177-86.

28. Lisot C.L.A., Silla L.M.R. Screening for hemoglobinopathies in blood donors from Caxias do Sul, Rio Grande do Sul, Brasil: prevalence in na Italian colony. Caderno de Saúde Pública 2004;20:1595-601.

29. Sobreira A.C.M., Gomes F.V.B.A.F., Silva M.A.M., Oliveira M.F. Chagasic infection prevalence in blood donors for the Hemocentro Regional de Iguatu. Revista da Sociedade Brasileira de Medicina Tropical 2001;34:193-6.

30. Kamiji M.M., Oliveira R.B. Features of Chagas' disease patients with emphasis on digestive form in a tertiary hospital of Ribeirão Preto. Rev Soc Bras Med Trop 2005;38:305-9. 
31. Oelemann W.M., Teixeira M.D., Verissimo da Costa G.C., et al. Evaluation of three commercial enzyme-linked immunosorbent assays for diagnosis of Chagas'disease. J Clin Microbiol 1998;36:2423-7.

32. Ferreira A.W., Belem Z.R., Moura M.E.G., Camargo M.E. Aspectos da padronização de testes sorológicos para a doença de Chagas. Um teste imunoenzimático para a triagem de doadores de sangue. Revista do Instituto de Medicina Tropical de São Paulo 1991;33:123-8.

33. Hamerschlak N., Pasternak J., Amato Neto V., et al. Chagas disease: an algorithm for donor screening and positive donor counseling. Rev Soc Bras Med Trop 1997;30:205-9.

34. Fuchs AP, Fioratti VL, de Mello VA, Boainain E. Serological diagnosis of Chagas' disease. Comparative study of various technics. Rev Inst Med Trop São Paulo 1980;22:242-5.

35. Camargo M.E., Hoshino-Shimizu S., Macedo V., et al. Serologic diagnosis of human Trypanosoma cruzi infection. Comparative study of complement fixation, immunofluorescence, hemagglutination and floculation tests in 3,624 serum samples. Rev Inst Med Trop São Paulo 1977;19:254-60.

36. Gadelha AA, Vercosa AF, Lorena VM, et al. Chagas‘ diseade diagnosis: comparative analysis of recombinant ELISA with conventional ELISA and the haemagglutination test. Vox Sang 2003;85:165-70.

37. Schmunis G.A. Trypanosoma cruzi, the etiologic agent of Chagas' disease: status in the blood supply in endemic and nonendemic countries. Transfusion 1991;31:547-57.

38. Saldana A., Souza O.E. Trypanosoma rangeli: epimastigote immunogenicity and cross-reaction with Trypanosoma cruzi. J Parasitol 1996;82:363-6.

39. Zambrano-Villa S., Rosales-Borjas D., Carrero J.C., et al. How protozoan parasites evade the immune response. Trends Parasitol 2002;18:272-8.

40. Garcia I.E., Lima M.R., Marinho C.R., et al. Role of membranebound IgM in Trypanosoma cruzi evasion from immune clearance. J Parasitol 1997;83:230-3.

41. Machado C.R., Augusto-Pinto L., McCulloch R., Teixeira S.M. DNA metabolism and genetic diversity in Trypanosomes. Mutation Research 2006;612:40-57.

42. El-Sayed N.M., Myler P.J., Bartholomeu D.C., et al. The genome sequence of trypanosoma cruzi, etiologic agent of Chagas disease. Science 2005;309:409-15.
43. Macedo A.M., Machado C.R., Oliveira R.P., Pena S.D. Trypanosoma cruzi: genetic structure of populations and relevance of genetic variability to the pathogenesis of chagas disease. Mem Inst Oswaldo Cruz 2004;99:1-12.

44. Toledo M.J., Bahia M.T., Veloso V.M., et al. Effects of specific treatment on parasitological and histopathological parameters in mice infected with different Trypanosoma cruzi clonal genotypes. J Antimicrob Chemother 2004;53,1045-53.

45. Umezawa E.S., Nascimento M.S., Kesper Jr. N., et al. Immunoblot assay using excreted-secreted antigens of Trypanosoma cruzi in serodiagnosis of congenital, acute, and chronic Chagas'disease. J Clin Microbiol 1996;34:2143-7.

46. Luz Z.M.P., Coutinho M.G., Cançado J.R., Krettli A.U. Hemoculture: sensitive technique in the detection of Trypanosoma cruzi in chagasic patients in the chronic phase of Chagas disease.Rev Soc Bras Med Trop 1994; 27:143-8.

47. Pinto PLS. Circulação e caracterização de Trypanosoma cruzi isolados de mamíferos silvestres capturados no Estado de São Paulo, Brasil. Revista do Instituto de Medicina Tropical São Paulo 2001;43:44.

48. Gomes M.L., Galvão L.M., Macedo A.M., et al. Chagas‘disease diagnosis: comparative analysis of parasitologic, molecular, and serologic methods. Am J Trop Med Hyg 1999;60(2):20510.

49. Hernandez-Becerril N., Mejia A.M., Ballinas-Verdugo M.A., et al. Blood transfusion and iatrogenic risks in Mexico city. AntiTrypanosoma cruzi seroprevalence in 43,048 blood donors, evaluation of parasitemia, and electrocardiogram findings in seropositive. Mem Inst Oswaldo Cruz 2005;100(2):111-6.

50. Franco Y.B.A., Silva I.G., Rassi A., et al. Correlation among the positivity of the artificial xenodiagnosis and the amount of blood and triatomines used in the exam, in chronic chagasic patients. Revista da Sociedade Brasileira de Medicina Tropical. 2002;35:29-33.

51. Dias C., Nussenzweig V., Gonçales A. An improved polymerase chain reaction assay to detect Trypanosoma cruzi in blood. Am J Trop Med Hyg 1992;46:616-23.

52. Lucheis S. B., Da Silva A. V., Araújo Jr. J.P., et al. Trypanosomatids in dogs belonging to individuals with chronic Chagas' disease living in Botucatu town and surrounding region, São Paulo State, Brazil. Journal of Venomous Animals and Toxins including Tropical Diseases 2005;11:492-509. 